\title{
Experiment on the Segment Model of a Plain Concrete Arch Bridge Reinforced with UHPC Composite Arch Circle
}

\author{
Zongshan Wang $\mathbb{D}^{1},{ }^{1}$ Jianting Zhou $\mathbb{D}^{1},{ }^{1}$ Jun Yang $\mathbb{D},{ }^{1}$ Lei Chen, ${ }^{2}$ and Weicheng Wang ${ }^{1}$ \\ ${ }^{1}$ State Key Laboratory of Mountain Bridge and Tunnel Engineering, Chongqing Jiaotong University, Chongqing 400074, China \\ ${ }^{2}$ Chongqing Municipal Design and Research Institute, Chongqing 400000, China
}

Correspondence should be addressed to Jun Yang; yangjun@mails.cqjtu.edu.cn

Received 7 February 2020; Revised 28 May 2020; Accepted 2 June 2020; Published 13 August 2020

Academic Editor: Xueping Fan

Copyright (C) 2020 Zongshan Wang et al. This is an open access article distributed under the Creative Commons Attribution License, which permits unrestricted use, distribution, and reproduction in any medium, provided the original work is properly cited.

\begin{abstract}
This research aims to investigate the efficiency of strengthening of plain concrete (PLC) arches using UHPC. Thirteen segment arch models reinforced using normal concrete (NC, group $N$ ) or ultra-high performance concrete (UHPC, group $U$ ) were tested in this study. The failure mode, strain distribution, and calculation of bearing capacity of PLC arch bridges reinforced with UHPC arch circle were analyzed. The experimental results showed that the technology of chiseling and planting bars could provide sufficient bond strength on the interface between the UHPC reinforcement layer and NC substrate. Both groups showed one or two failure modes of the concrete crushing of the original structure and the interface failure. However, no cracks appeared in the UHPC reinforcement layer, indicating that there was still large bearing potential. The strain distribution of the whole section in group $N$ was consistent with the plane section assumption. But, this phenomenon was not observed in group $U$ since the strain of the reinforcement layer was ahead (R-side loading) or behind (L-side loading) that of original structures. A simplified calculation formula was used for calculating the bearing capacity of group $U$. It was accurate for specimens loaded on the L-side, and an enhancement coefficient of 0.15 should be considered for R-side loading specimens.
\end{abstract}

\section{Introduction}

There are a large number of masonry arch bridges, referring to stone and PLC arch bridges, generally built in the 1960s-1980s in the secondary highways in Southwest China. Though the span of such arch bridges is small, generally no more than $20 \mathrm{~m}$, they have made an important contribution to the development of national economy. However, with the increase of service time and the change of traffic volume, a large number of masonry arch bridges have been damaged in varying degrees. Maintenance and reinforcement are economic and reasonable choices because of the high cost of demolition and reconstruction.

The conventional retrofitting techniques found in the literature are the application of steel profiles at the arch intrados, the use of reinforced concrete hoods, and the introduction of a reinforced concrete layer at the arch intrados or extrados. Due to the material incompatibility, steel profiles are no longer used in the retrofitting of a solid masonry arch bridge. Similarly, it is difficult to use reinforced concrete hoods because of the long construction period and high construction cost for removal and reconstruction of a superstructure. So, the most suitable method for the reinforcement of solid arch bridge is composite arch circle at the arch intrados. In order to ensure the reinforcement effect, the thickness of the general reinforcement layer of the conventional composite arch circle method is over $30 \mathrm{~cm}$, which leads to extra self-weight and aesthetic incompatibility. At the same time, the clearance under the bridge is greatly reduced, which will seriously affect the flood discharge under the bridge during the flood period.

In the past ten years, the research of composite material strengthening arch bridge has become a hot spot, and a variety of new materials have emerged. To sum up, it can be roughly divided into two categories: one is fiber-reinforced polymers (FRPs), including CFRP and GFRP. Applying the FRP strips could lead to an increase in the failure load of the arch, change the cracking pattern, and significantly reduce 
the deflection [1-4]. Three strengthening schemes, including the bonding method, wrapping method, and bonding/anchoring method, were suggested by researchers after studying performances of bridge arches strengthened by FRP, and the wrapping method was the most efficient $[5,6]$. Although the bearing capacity of an arch reinforced with FRP was greatly increased, several drawbacks of the FRP must be underlined as a narrow working temperature range, inability to apply FRP on wet surfaces, and its fragility. Moreover, in many heritage cases, epoxy resins are totally forbidden for their incompatibility with substrates [7]. The other one which has been recently proposed as an alternative for strengthening masonry arches is innovative composites made of a fabric embedded in a cement-based mortar (FRCM, Fabric-Reinforced Cementitious Mortar). Poliparafenilenbenzobisoxazole (PBO), carbon, glass, and basalt fibers are the representative fiber textile [8]. Compared to FRPs, these composites present many advantages as higher moisture permeability, compatibility with the masonry substrate, and reversibility [9]. They have been applied for the strengthening of masonry arches at the intrados $[8,10]$ or extrados $[7,11]$ or both $[12]$. Results have shown that the mortar allowed an intervention more compatible with masonry compared with resin, but the increase in strength was significantly lower than that achieved by means of FRP composites, and repair work was very difficult to carry out in the actual project because the total layer should be controlled to $6-8 \mathrm{~mm}$ and must be divided into three steps $[8,12]$.

Recently, the use of ultra-high performance concrete (UHPC) for the strengthening of structures has caught the attention of researchers [13]. Superior mechanical performance, excellent antiseismic property, and resistance against environmental degradation are the advantages of UHPC compared with the common concrete [14-16]. In the last few years, the possibility of using UHPC for the strengthening of RC structures has been investigated in beams [17-20], columns [21, 22], joints [23], and shear walls [24, 25], and the result has shown the effectiveness of this retrofit technique. The most successful application of UHPC till now in the field of structural repair and reinforcement is using UHPC materials instead of the traditional paving materials to improve the toughness and durability of the deck pavement [26].

In this paper, the use of UHPC as an alternative to other available strengthening techniques such as FRP or FRCM composites for the strengthening of PLC arches is studied. To analyze the failure mode, strain distribution, and bearing capacity of a PLC arch bridge reinforced with UHPC arch circle, 15 segment models, of which 2 were not reinforced, 4 were reinforced with $\mathrm{NC}$, and 9 were reinforced with UHPC, were designed for eccentric compression experiment. Eccentricity, the loading direction, and the thickness of the reinforcing layer were chosen as variable parameters. The bearing capacity of the segment model was calculated according to the distribution of strain on the section, and a simple method for the convenience of engineering application was developed based on the literature [27].

\section{Experimental Program}

Considering the complexity of arch fabrication, the failure mode, strain distribution, and bearing capacity of a PLC arch bridge reinforced with UHPC arch circle were analyzed by segment models.

2.1. Fabrication of Segment Models. The segment models in the current study consisted of the fabrication of 15 PLC column specimens: 2 column specimens were reference columns, whereas 4 column cores were repaired by $\mathrm{NC}$ on one side and the rest were strengthened by UHPC unilaterally. The details of the fabricated column specimens are as follows:

(1) Two PLC column specimens, recorded as group $P$, were cast monolithically to act as unreinforced reference columns. They had cross-sectional dimensions of $200 \mathrm{~mm} \times 140 \mathrm{~mm}$ and a height of $800 \mathrm{~mm}$. In order to prevent local crushing affecting the final bearing capacity, a $200 \mathrm{~mm}$ concrete end reinforced with $12 \mathrm{~mm}$ longitudinal bars (HRB335) and 8 stirrups (HPB300) was set at both ends, so the total height of reference columns was $1200 \mathrm{~mm}$, as shown in Figure 1.

(2) Thirteen PLC columns with the section size of $200 \mathrm{~mm} \times 140 \mathrm{~mm}$ and a height of $800 \mathrm{~mm}$ were cast to reinforce. It should be noted that there was a $100 \mathrm{~mm}$ concrete end with the same longitudinal bars and stirrups at both ends. Meanwhile, the longitudinal reinforcement of the end was extended $80 \mathrm{~mm}$ for the subsequent end construction.

(3) When these 13 PLC columns were strengthened, four were strengthened by $\mathrm{NC}$ with a $70 \mathrm{~mm}$ reinforcement layer, recorded as group $N$, eight were strengthened by UHPC with a $35 \mathrm{~mm}$ reinforcement layer, and the last one was strengthened by UHPC with a $70 \mathrm{~mm}$ reinforcement layer, recorded as group $U$. Three HRB335 bars with a diameter of $12 \mathrm{~mm}$ were set in the middle of the reinforcement layer, and a concrete segment of $100 \mathrm{~mm}$ long at both ends of each test piece was poured together with the reinforcement layer concrete to enhance the local performance and maintain the same height level with group $P$. Figure 2 shows the details of specimens with a $70 \mathrm{~mm}$ reinforcement layer before and after reinforcement.

(4) The upper or lower edge of the solid arch bridge may be pressed heavily under the action of external load, so loading direction and eccentricity are the variable parameters in this test. Considering the inconsistency between the elastic modulus of the reinforcement layer and the original structural material, the neutral axis was determined by the conversion of the elastic modulus. There were two kinds of loading directions here, $L$ and $R$, which meant the load far from or close to the reinforcement layer, respectively. Table 1 shows the details of 15 segment models. Here, specimens were named as type $(P, N$, and $U)$ followed by 

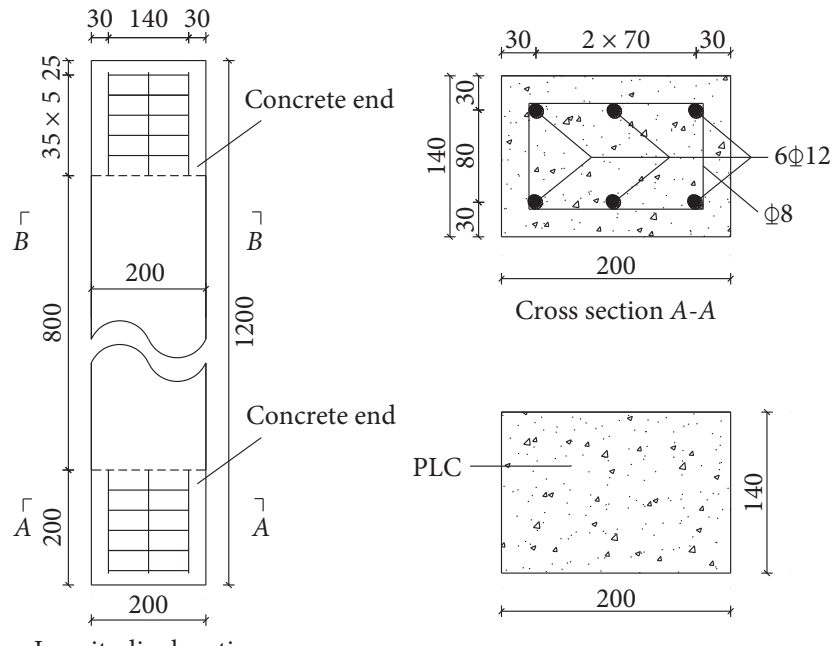

Longitudinal section

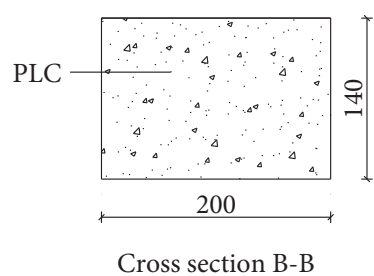

FIGURE 1: Unreinforced specimens details.
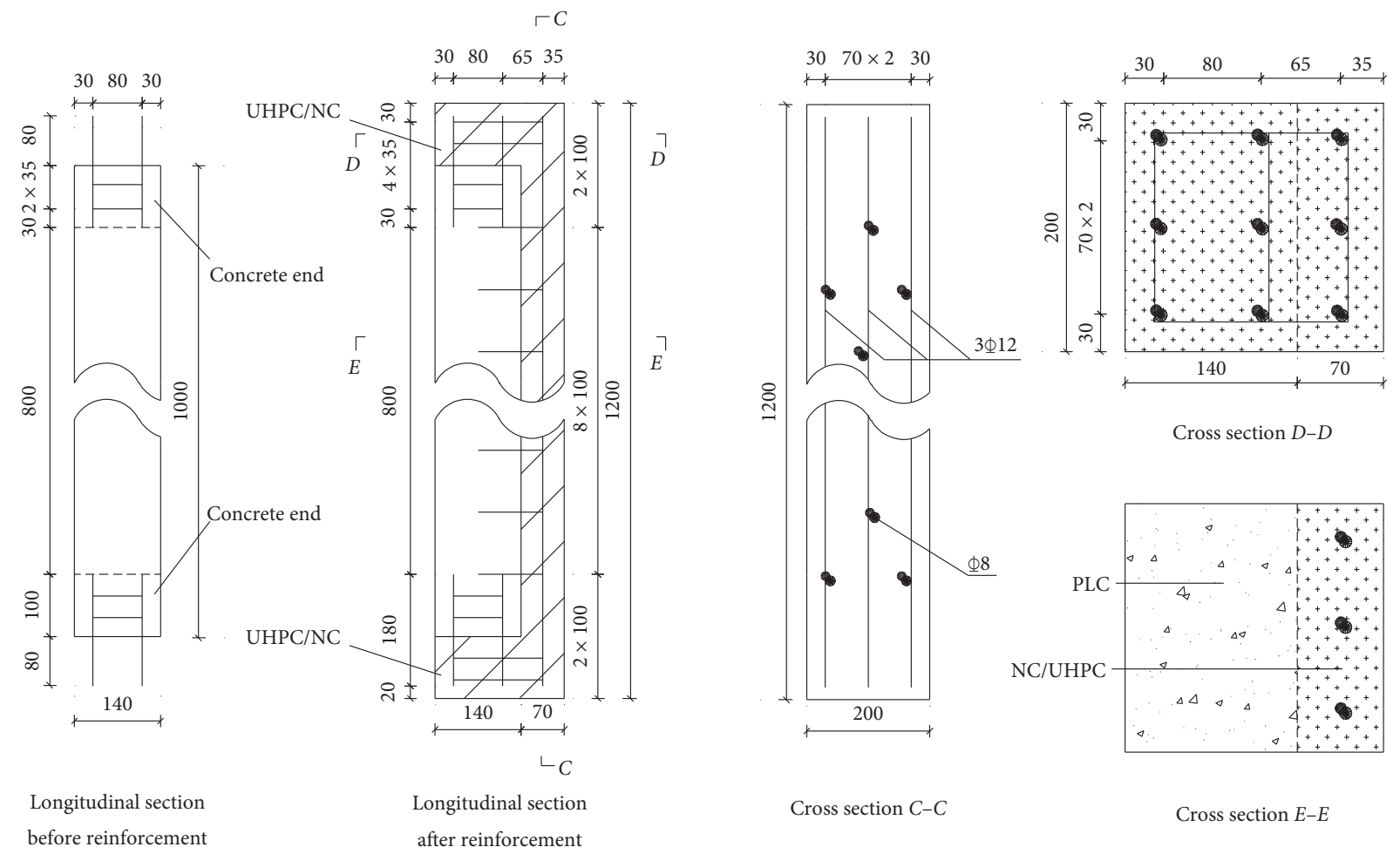

Figure 2: The details of the specimen with a $70 \mathrm{~mm}$ reinforcement layer.

reinforcement layer thickness-loading direction-eccentricity-batch. For instance, U35-L-20-1 means this specimen is the NO.1 segment model reinforced with a $35 \mathrm{~mm}$ UHPC layer, the load is far from reinforcement layer, and the eccentricity is $20 \mathrm{~mm}$.

2.2. Types of Concrete Mixes. In this research, the following concrete mixes are designed on the basis of the targeted concrete compressive strength.
The C40 mix was prepared and used to cast group $P$ and the original structures of group $N$ and $U$. Table 2 shows the C40 mixing proportions. The average compression strength, determined by the uniaxial compressive test on 3 standard $100 \mathrm{~mm}$ cubes, was equal to $44.6 \mathrm{MPa}$.

The C50 mix with a maximum aggregate size of $25 \mathrm{~mm}$ was prepared and used to cast the reinforcement layer of group $N$. Table 3 shows the mixing proportions of C50. The average compression strength, determined by the uniaxial compressive test on 3 standard $100 \mathrm{~mm}$ cubes, was equal to $50.2 \mathrm{MPa}$. 
Table 1: Details of segment models.

\begin{tabular}{|c|c|c|c|c|c|c|c|}
\hline$\#$ & $\begin{array}{l}\text { Reinforcement } \\
\text { materials }\end{array}$ & $\begin{array}{l}\text { Reinforcement } \\
\text { thickness (mm) }\end{array}$ & $\begin{array}{l}\text { Eccentricity } \\
(\mathrm{mm})\end{array}$ & $\begin{array}{c}\text { Original } \\
\text { section } \\
(\mathrm{mm})\end{array}$ & $\begin{array}{l}\text { Overall cross } \\
\text { section } \\
(\mathrm{mm})\end{array}$ & Notation & Number \\
\hline 1 & \multirow{3}{*}{ NO } & 0 & 0 & $200 \times 140$ & $200 \times 140$ & P00-L00 & 1 \\
\hline 2 & & 0 & 30 & $200 \times 140$ & $200 \times 140$ & P00-L30 & 1 \\
\hline 3 & & 70 & 0 & $200 \times 140$ & $200 \times 210$ & N70-L00 & 1 \\
\hline 4 & \multirow{3}{*}{$\mathrm{NC}$} & 70 & 20 & $200 \times 140$ & $200 \times 210$ & N70-L20 & 1 \\
\hline 5 & & 70 & 30 & $200 \times 140$ & $200 \times 210$ & N70-L30 & 1 \\
\hline 6 & & 70 & 40 & $200 \times 140$ & $200 \times 210$ & N70-L40 & 1 \\
\hline 7 & \multirow{5}{*}{ UHPC } & 35 & 20 & $200 \times 140$ & $200 \times 175$ & U35-L20 & 2 \\
\hline 8 & & 35 & 40 & $200 \times 140$ & $200 \times 175$ & U35-L40 & 2 \\
\hline 9 & & 35 & 20 & $200 \times 140$ & $200 \times 175$ & U35R20 & 2 \\
\hline 10 & & 35 & 30 & $200 \times 140$ & $200 \times 175$ & U35R30 & 2 \\
\hline 11 & & 70 & 20 & $200 \times 140$ & $200 \times 210$ & U70-L20 & 1 \\
\hline
\end{tabular}

TABLE 2: C40 mix proportion.

\begin{tabular}{lcccc}
\hline Components Cement & $\begin{array}{c}\text { Fine aggregate } \\
\text { (sand) }\end{array}$ & $\begin{array}{c}\text { Coarse } \\
\text { aggregate }\end{array}$ & Water \\
\hline Mass ratio & 1.000 & 1.290 & 2.880 & 0.39 \\
\hline
\end{tabular}

The UHPC mix was used to cast the reinforcement layer of group $U$. The mix proportion of UHPC material is summarized in Table 4. In addition, the straight-shaped steel fibers with a diameter of $0.12 \mathrm{~mm}$ and a length of $8 \mathrm{~mm}$ and with a tensile strength of $2200 \mathrm{MPa}$ were mixed. The volume percentage of steel fibers was fixed at $2 \%$. All required amounts of constituent materials were weighed accurately and mixed properly using a tilting revolving drum mixer to produce homogeneous concrete. The average compression strength of UHPC, measured by the compressive test using three standard $100 \mathrm{~mm}$ cubes, was equal to $133.5 \mathrm{MPa}$, and the elastic modulus of UHPC, verified by the compressive test on six prisms $\left(100 \times 100 \times 300 \mathrm{~mm}^{3}\right)$, was equal to $45.0 \mathrm{GPa}$.

\subsection{Preparation of $P$ and the Unreinforced Part of $N$ and $U$.} In the indoor test, considering the difficulty of masonry pouring and the wide application of concrete in masonry arch bridge, the concrete was used as the raw structural material in this experiment. In the actual bridge reinforcement, the strength level of the reinforcement layer material was one level higher than that of the original structure [28], and C40 was selected as the raw structural material and C50 as the reinforcement layer material. Group $P$ and the unreinforced part of group $N$ and $U$ after pouring are shown in Figure 3.

Two kinds of steel bars with different diameters were used in this test: the $12 \mathrm{~mm}$ diameter steel bars were used as the longitudinal steel bars of reinforcement layer and concrete end, and the $8 \mathrm{~mm}$ steel bars were used as end stirrups and embedded steel bars. Tests were carried out for each bar size: three steel specimens with a length of $300 \mathrm{~mm}$ for a diameter of $12 \mathrm{~mm}$ and $8 \mathrm{~mm}$. All steel samples were obtained from randomly chosen bars. Table 5 shows the testing results of the two kinds of steel reinforcements.
TABLE 3: C50 mix proportion.

\begin{tabular}{lcccc}
\hline Components & Cement & $\begin{array}{c}\text { Fine aggregate } \\
\text { (sand) }\end{array}$ & $\begin{array}{c}\text { Coarse } \\
\text { aggregate }\end{array}$ & Water \\
\hline Mass ratio & 1.000 & 1.140 & 1.880 & 0.38 \\
\hline
\end{tabular}

2.4. Preparation of the Reinforcement Layer. Mechanical drilling with a $10 \mathrm{~mm}$ diameter drilling bit was conducted to perforate a hole with a diameter of $10 \mathrm{~mm}$ and a depth of $70 \mathrm{~mm}$ in accordance with the JTG/T J22-2008 standards [28]. The drilled holes were filled with the Hilti HIT-RE 500 bonding material to ensure a good bond between the shear connectors and old concrete. L-shaped shear connectors with a diameter of $8 \mathrm{~mm}$ and a total length of $105 \mathrm{~mm}$ (70 mm layer) or $87.5 \mathrm{~mm}$ ( $35 \mathrm{~mm}$ layer) were used. The $70 \mathrm{~mm}$ straight portion of the shear connector was inserted in the drilled hole. In the middle of the reinforcement layer, 3 steel-reinforcing bars with a length of $1160 \mathrm{~mm}$ and a diameter of $8 \mathrm{~mm}$ were used.

The main procedures were as follows: the concrete columns to be reinforced were placed in timber molds, and then, C50 concrete was poured for reinforcement. They were cast from the same batch of C50 mix and compacted mechanically using a hand tamping rod to prevent segregation and honeycombing. The sides of timber molds were stripped away after being left for $24 \mathrm{~h}$. Then, they were placed in the environment of $20^{\circ} \mathrm{C}$ and $95 \%$ humidity for standard curing for 28 days.

Due to the self-leveling property, after the UHPC was cast in the timber molds, the surfaces were smoothed by trowelling. The molds were removed after the test pieces were left for 24 hours. After the removal, they were cured with $95^{\circ} \mathrm{C}$ steam for 48 hours. Finally, they were placed in the environment of $20^{\circ} \mathrm{C}$ and $95 \%$ humidity for standard curing until 28 days.

2.5. Testing of Specimens. In order to realize the eccentric load of the test piece, the position of two square steel plates with a thickness of $5 \mathrm{~mm}$ at the top of the specimen was mainly adjusted in this experiment. One steel plate was placed on the top of the specimen to make the force transmit evenly, and another one was used to realize the 
TABLE 4: UHPC mix proportion.

\begin{tabular}{lcccccc}
\hline Components & Cement & Silica fume & Quartz sand & Quartz flour & Water reducer & Water \\
\hline Mass ratio & 1.000 & 0.250 & 1.100 & 0.300 & 0.019 & 0.225 \\
\hline
\end{tabular}

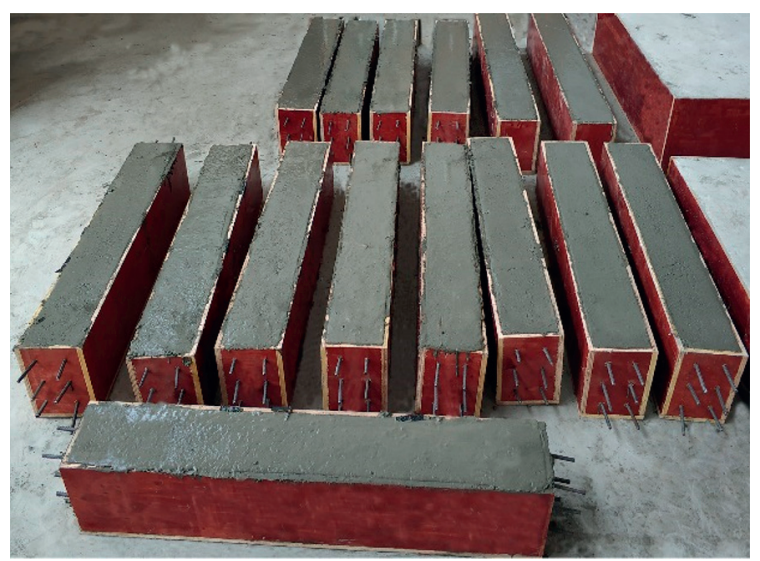

FIgURE 3: Segment model pouring.

eccentric loading of the specimens by changing the position.

At the age of 28 days, specimens were stored in a dry place for 10-15 minutes to obtain a dry surface condition, and then, specimens were placed carefully on the testing machine. A YAW-10000F Press machine was used in the test, and the loading was controlled by force with a loading rate of $3 \mathrm{kN} / \mathrm{s}$. Five strain gauges were pasted on the surface of the middle section of the specimen to measure its longitudinal strain. Three were located in the original structure, and two were located in the reinforcement layer, which were recorded as 1-5 \#, as shown in Figure 4. They were used to test the strain changes of the original structure and the reinforcement layer in the whole loading process, and the results provided reference for the analysis of the bearing capacity distribution of the original structure and the reinforcement layer. The loading diagram of the specimen is shown in Figure 4.

\section{Results and Discussion}

3.1. Failure Characteristics and Cracks. Tests of the failure characteristics and cracks of all specimens were performed. For unreinforced specimens, due to the lack of longitudinal reinforcement, there was brittle failure under axial and eccentric compression loads. When the load reached $75 \%$ of the ultimate load of P00-L-00, concrete cracks appeared around the middle part of the specimen, and then, the cracks increased, accompanied by concrete peeling, making the compression area rapidly smaller, and finally, the specimen broke and crushed. The failure mode of eccentric compression member P00-L-30 was similar, and failure photos could not be obtained in time because the failure speed was very fast.

For specimens strengthened with NC, when the bearing capacity of N70-L-00 specimen reached about $90 \%$ of the peak value, microcracks appeared at the junction of the old and new structures on the top of the original structure. With the increase of the load, the cracks continued to develop, and then, there were sporadic concrete blocks falling. At the moment when the ultimate bearing capacity reached, the cracks ran through the original structure from the top to the bottom. At the same time, cracks visible appeared at the interface and the side of the reinforcement layer. When the bearing capacity of the N70-L-20 test piece reached about $90 \%$ of the peak value, there were several longitudinal cracks in the upper and middle parts of the compression area of the specimen, and the cracks continued to develop and intersected with each other until the surface concrete block fell off with the increase of the load. At the moment of reaching the ultimate bearing capacity, a longitudinal main crack developed rapidly to the top at the interface in the upper half of the specimen, and a visible crack appeared on the reinforcement layer. The failure process of N70-L-30 and N70-L40 were similar to that of N70-L-20, both of which were longitudinal cracks in the middle and upper part of the specimen, then the cracks ran through, and finally, the peak load reached. However, it was worth noting that the interface was still intact, and no visible cracks were found on the reinforcement layer when N70-L-30 and N70-L-40 reached peak load. The damage photos of group $N$ are shown in Figure 5.

For the U35-L-20 and U35-L-40 specimens strengthened by UHPC, when they reached about $90 \%$ of the peak load, the original structural concrete on the side with larger compression on the top of the specimen first developed cracks, and then, the cracks penetrated each other, causing the concrete block to peel off, finally forming a groove in this area. The cracks rapidly extended from this area to both ends at the moment of breaking, and even some of the specimens showed the phenomenon of cracks running through the UHPC ends. However, no interface separation and cracks on the reinforcement layer occurred. For U35R-20 and U35-R-30 specimens, the failure phenomenon was different from the former two. The most significant feature was that the initial crack appeared at the interface of new and old concrete at the upper end. Also, the cracks expanded disorderly with the increase of load. The cracks diverged, and the interface showed obvious peeling when the specimens broke. The damage photos of group $U$ are shown in Figure 6.

In conclusion, the failure of group $P$ was sudden due to lack of longitudinal reinforcement. The concrete crushing of the original structure was the main failure of the group $N$, and the reinforcement layer of some specimens showed visible cracks. However, there were no cracks on the surface of the UHPC reinforcement layer in group $U$. The peeling of the interface and concrete crushing of original structure were the failure characteristics of R-side loading and L-side loading specimens for group $U$, respectively. 
TABLE 5: Steel reinforcement results.

\begin{tabular}{lcccc}
\hline Bar type & Diameter $(\mathrm{mm})$ & Yield stress $(\mathrm{MPa})$ & Ultimate tensile strength $(\mathrm{MPa})$ & Modulus of elasticity $(\mathrm{GPa})$ \\
\hline HRB300 & 8 & 363 & 413 & 215 \\
HRB335 & 12 & 372 & 427 & 215 \\
\hline
\end{tabular}

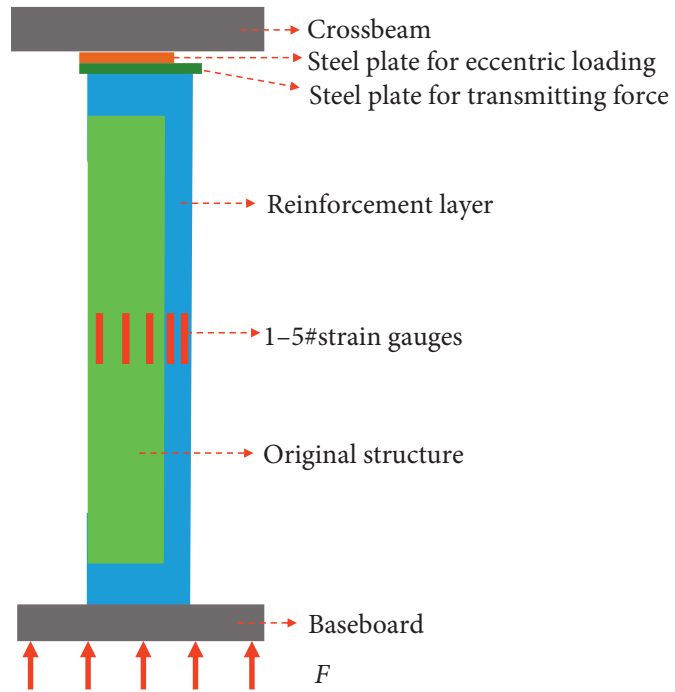

Figure 4: Segment model experimental setup.

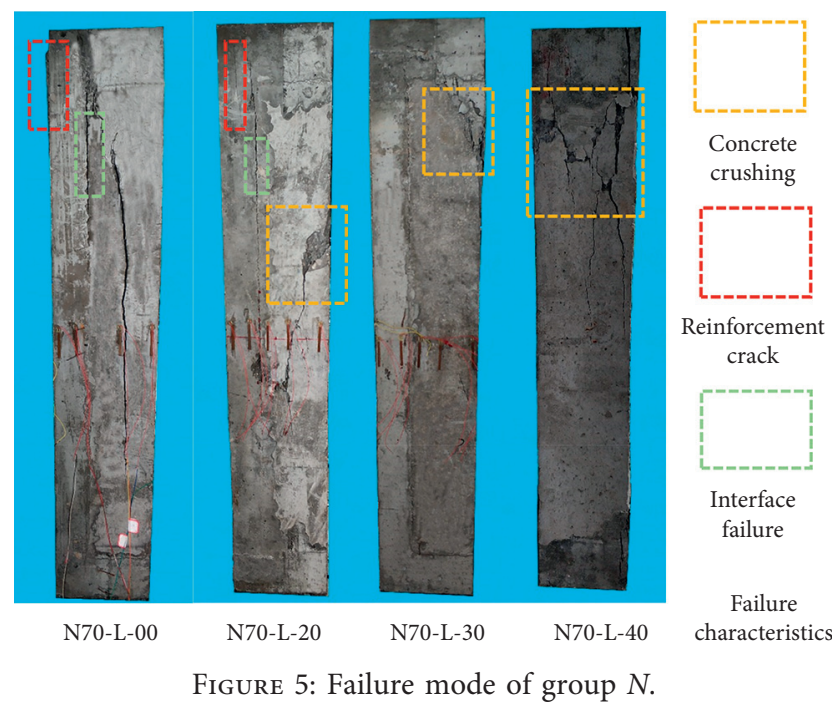

3.2. Strain Analysis of the Loading Section. The load versus strain curves of group $N$ specimens from loading to failure are plotted in Figure 7. It can be seen that the load versus strain curve of the N70-L-00 specimen is linear, and it has not entered the nonlinear stage. The data of four strains are very close, which is in good accordance with the characteristics of axial compression. The mean value of strain at failure is around $1300 \mu \varepsilon .4$ \# strain gauge in the N70-L-20 specimen was pasted close to the interface, whose value deviated greatly from that of other strain gauges during the collection process, so its value was removed during data processing. It can be seen that the load and strain collected from the strain gauge pasted on the original structure show a

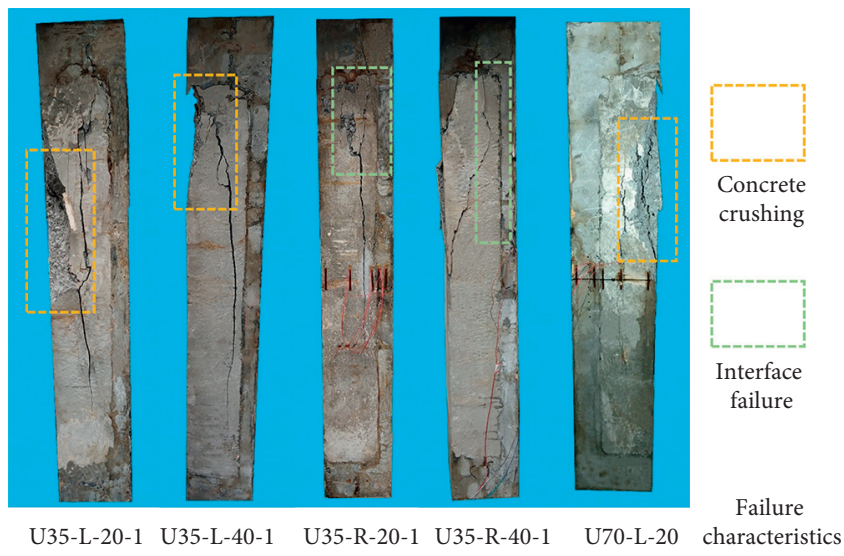

FigURE 6: Failure mode of group $U$.

linear relationship after $300 \mathrm{kN}$, and the strain growth rate obviously accelerates near the failure. Though the value of 5 \# strain gauge pasted on the new structure changes little before $1000 \mathrm{kN}$, its change after $1000 \mathrm{kN}$ is consistent with that of the other three. The load versus strain of N70-L-30 and N70-L-40 are similar to those of N70-L-20, but there are differences at the beginning and end of the linearity. Especially, the line of " $3 \#$ " in N70-L-30 is convex to the $y$-axis at the beginning. It may be that the two steel plates placed on the top of the test piece are not contacted well enough at the beginning of loading, so that the eccentricity is much greater than $30 \mathrm{~mm}$, actually forming a large eccentric compression, causing tension at position 3 \#. With the increase of load, the two steel plates are intimately attached, which can realize the force transmission and meet the eccentricity of the design, and the 3 \# strain returns to normal.

Figure 8 shows the load-strain curves of group $U$ specimens, which have the following two characteristics: (1) the load-strain curves can be divided into three stages: the stage of rapid load growth and slow strain growth in the initial stage, followed by the stage of gentle strain growth, and finally, the stage of abnormal strain before failure. (2) The largest compressive strain before failure is about $1300 \mu \varepsilon$, but the difference of the minimum compressive strain on the whole section is obvious. The minimum compressive strain of the L-side loading specimen is smaller than that of the R-side loading specimen. Under the same loading side, the minimum compressive strain of the specimen with larger eccentricity is smaller than that on the specimen with smaller eccentricity.

In order to facilitate the analysis of the strain distribution of the original structure and the reinforcement layer during the whole loading process, the position of each strain gauge pasted was accurately recorded (the farthest side from the reinforcement layer is the coordinate origin), and the connection line of the strain value measured under each load level is shown in Figures 9 and 10. 

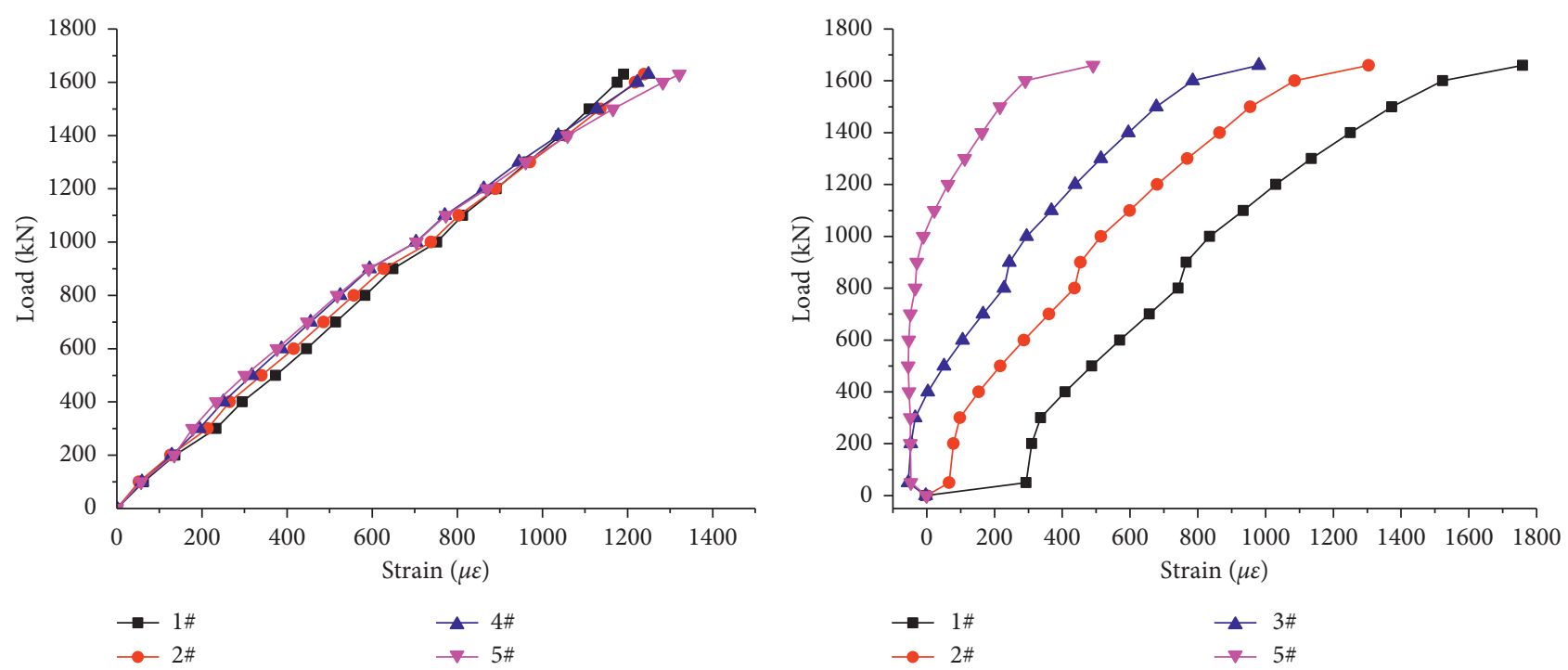

(a)

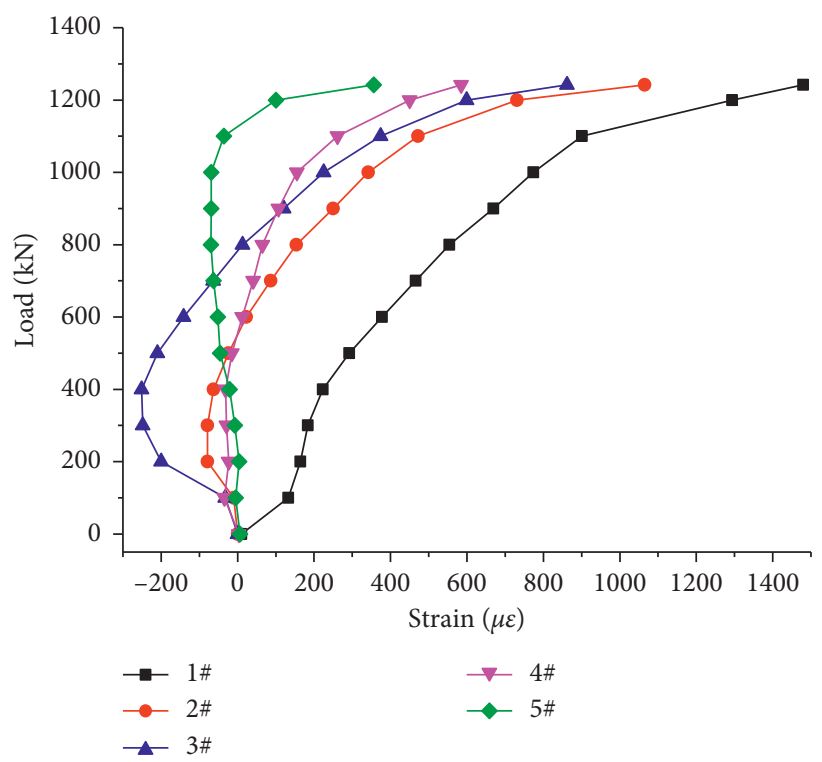

(c)

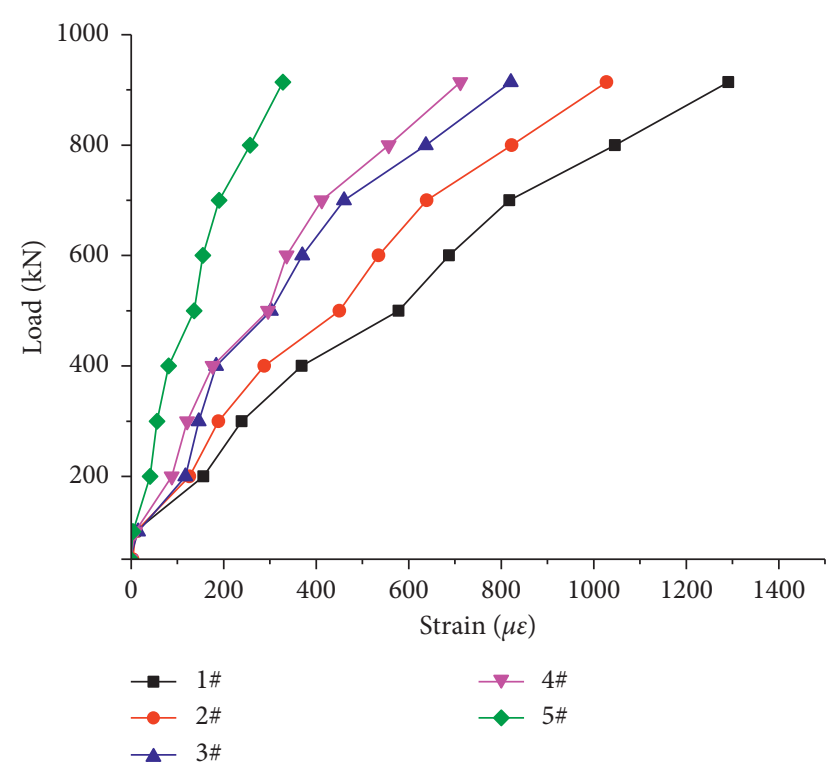

(d)

Figure 7: Load-strain diagrams of group N: (a) N70-L-00. (b) N70-L-20. (c) N70-L-30. (d) N70-L-40.

Figure 9 shows the strain distribution of group $N$ specimens throughout the loading process. For the axial compression specimen, the strain distribution of the whole section is approximately the same during the whole loading process, but there are some differences in other group $N$ specimens. When the load is small, the strain distribution is not in the same plane because the strain of the reinforcement layer changes little near $0 \mu \varepsilon$, lagging behind the original structure. When the load is larger, the strain of the whole section basically conforms to the plane section assumption.

The reason for this phenomenon is that the interface treatment in this test uses the technology of chiseling and planting bars without interface agents, and small gaps between the interfaces still exist. They hinder the transmission of force, and the bonded bars plays a small role in a small load. As the load increases, the effect of bonded bars is significantly enhanced, making the deformation of the whole section coordinating.

Figure 10 shows the strain distribution of group $U$ specimens throughout the loading process. Compared with group $N$, the section strain distribution of group $U$ does not satisfy the assumption of the plane section during the whole loading process, and the larger the load is, the more obvious the phenomenon is. For L-side loading specimens, the strain of the UHPC reinforcement layer always lags behind the original structure, but it always exceeds the original structure for R-side loading specimens. No cracks or slippage were observed in the UHPC-NC interface during the loading process. Only at the moment of failure of the R-side loading, the specimens developed the cracks, which shows that the interface treatment in this experiment is reliable, not the main factor of strain incongruity. The reason for this 

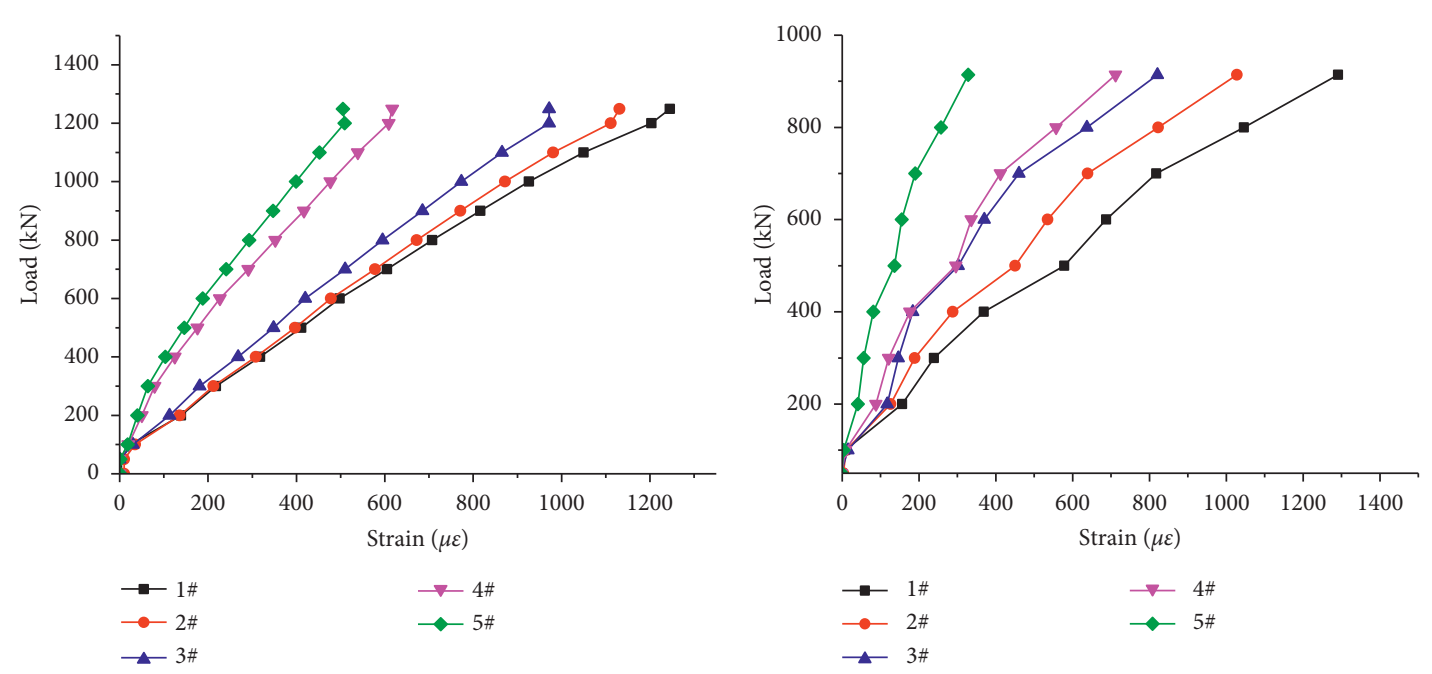

(a)
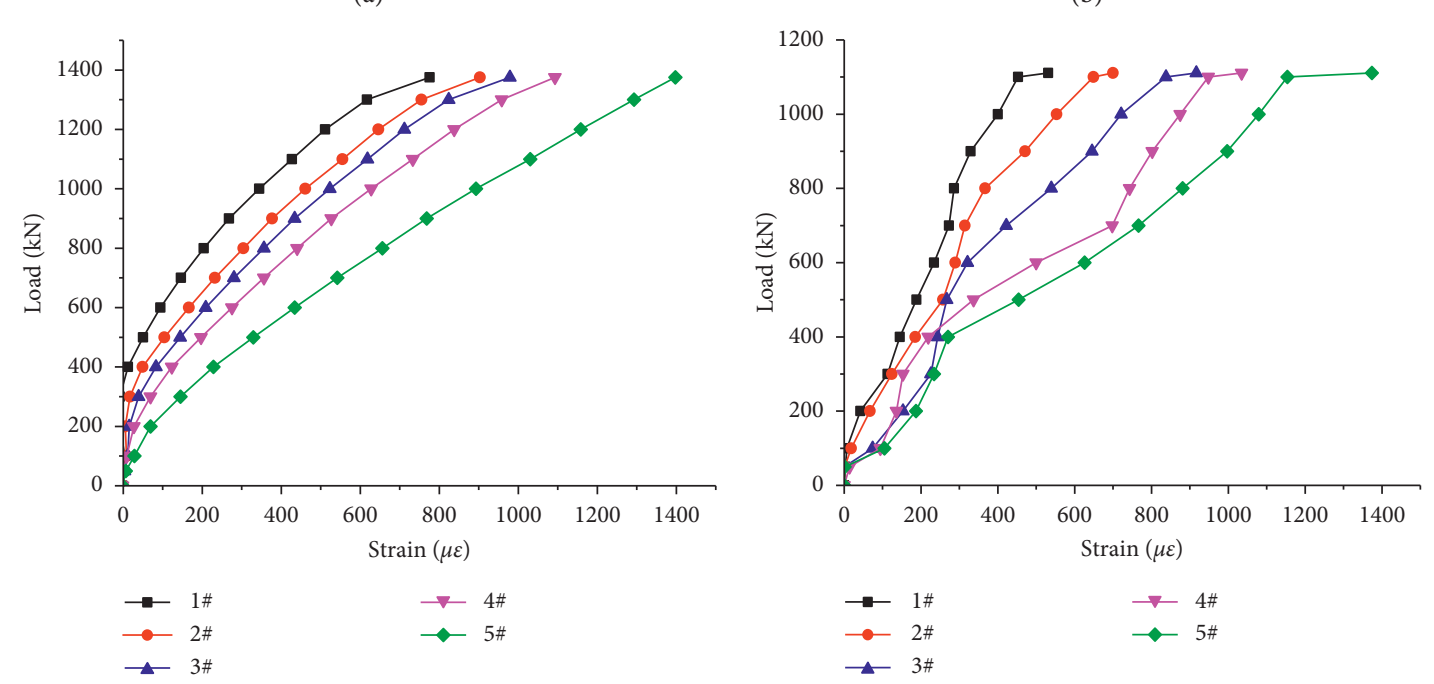

(c)

(d)

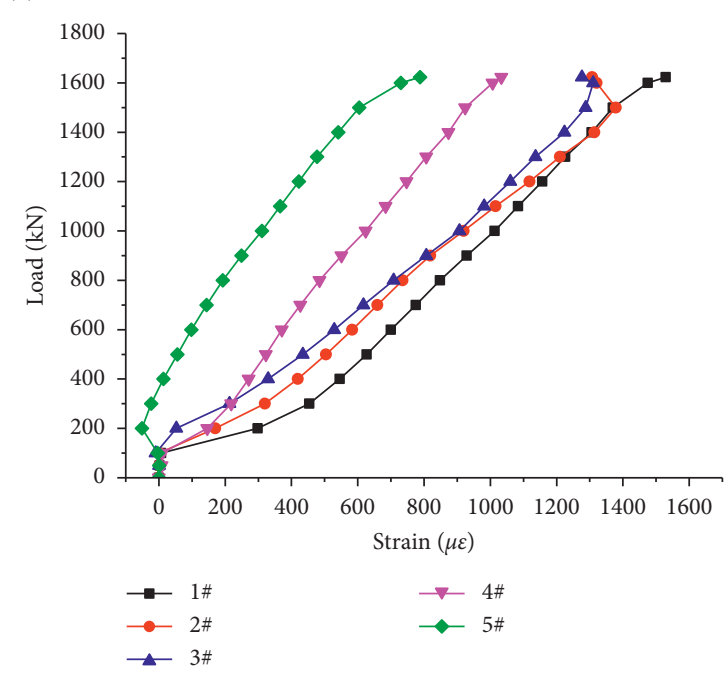

(e)

FIgURE 8: Load-strain diagrams of group U. (a) U35-L-20-1. (b) U35-L-40-1. (c) U35-R-20-1. (d) U35-R-30-1. (e) U70-L-20. 


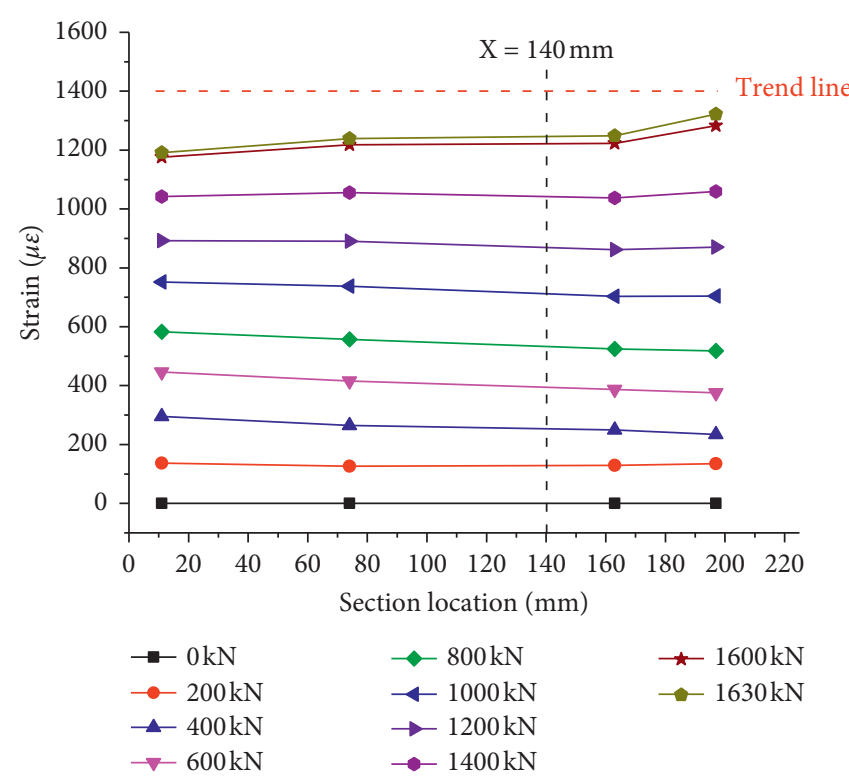

(a)

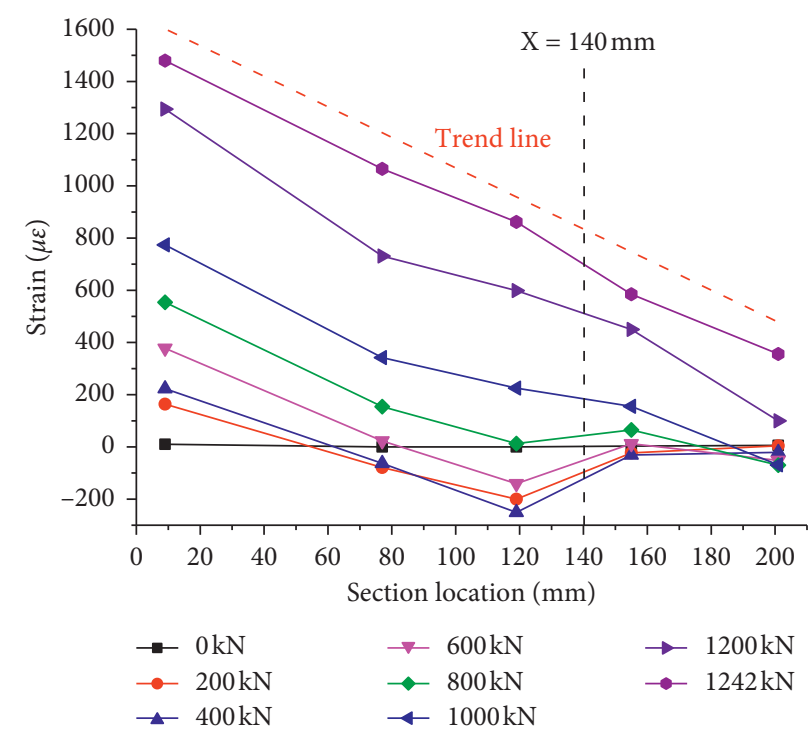

(c)

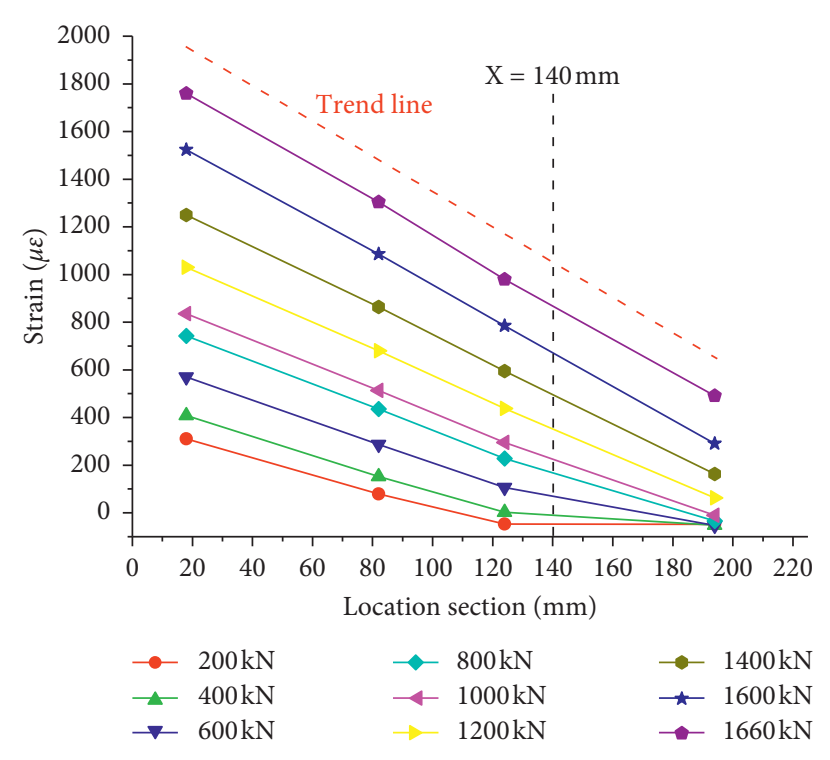

(b)

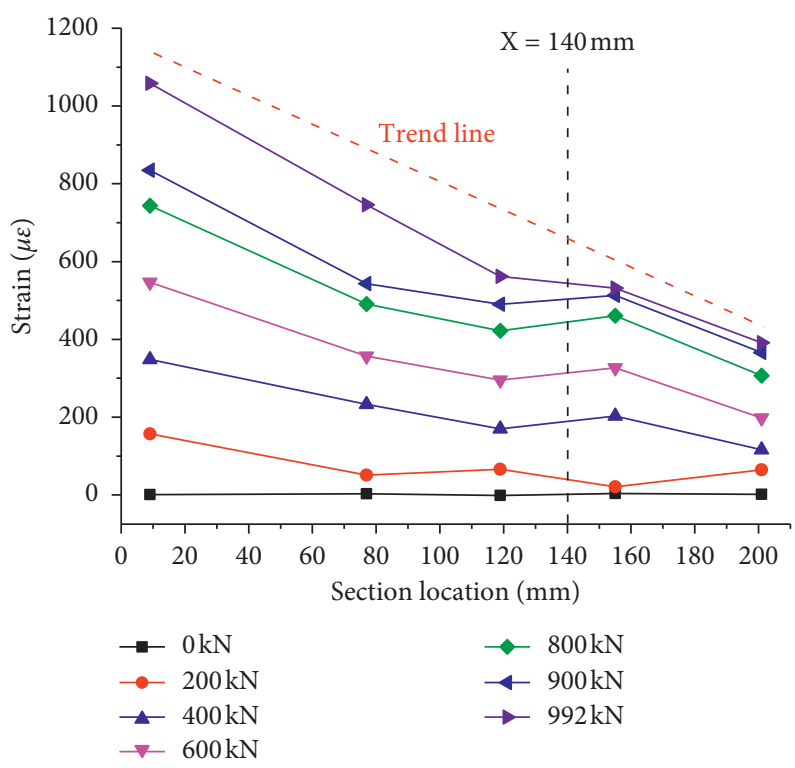

(d)

FIgURE 9: Strain distribution of group N. (a) N70-L-00. (b) N70-L-20. (c) N70-L-30. (d) N70-L-40.

phenomenon may be that the elastic modulus of UHPC is about 1.35 times that of NC.

3.3. Ultimate Bearing Capacity of the Segment Model. The measured values of bearing capacity of each specimen are summarized in Table 6 . It can be seen that the bearing capacity of a specimen under eccentric load is significantly lower than that of the axial compression specimen. With the increase of eccentricity, the bearing capacity of the specimen decreases gradually when the material of the reinforcement layer is the same. When the eccentricity and the thickness of the reinforcement layer are the same, the bearing capacity of the $\mathrm{R}$-side loading specimen is significantly higher than that of the L-side loading specimen because the peak compressive strain of UHPC is significantly higher than that of NC. When the thickness of the reinforcement layer is the same and both are loaded on the L-side, the UHPC reinforcement layer has no obvious improvement on the bearing capacity compared with the NC reinforcement layer.

The main reason is that the test ended when the original structure reached the peak compressive strain, but the UHPC reinforcement layer is intact without any cracks, and its strain is far lower than the peak compressive strain. It shows that the UHPC reinforcement layer still has great bearing potential. In fact, the failure process of the masonry arch bridge reinforced with the steel fiber-reinforced mortar 


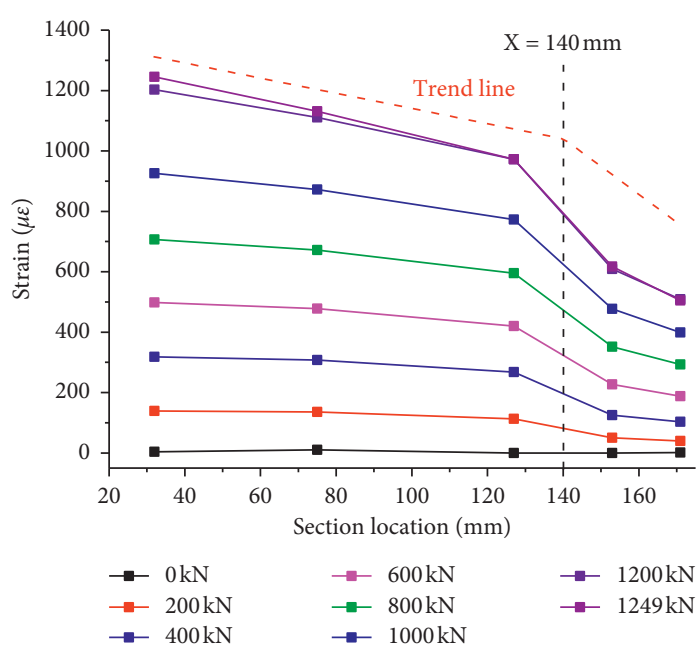

(a)

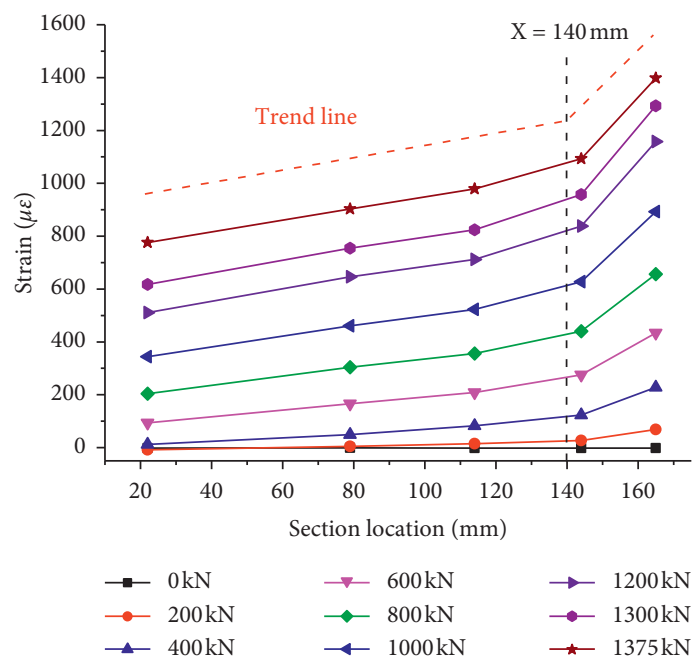

(c)

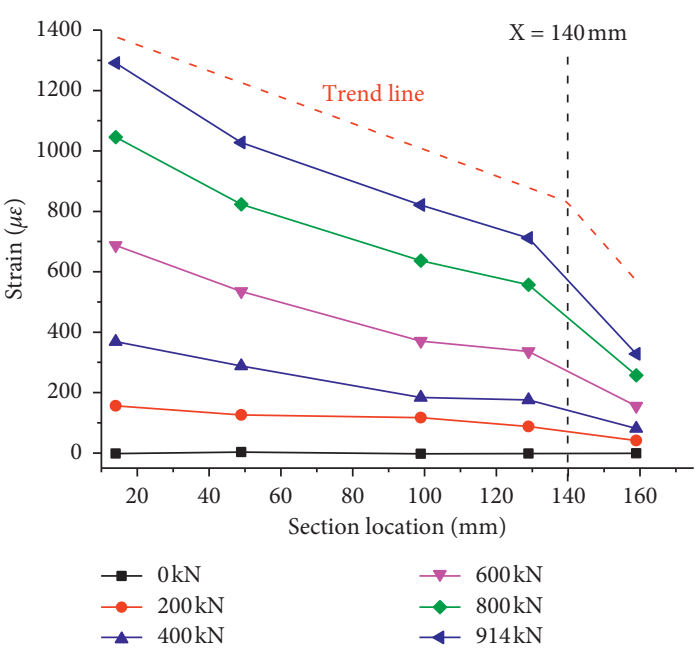

(b)

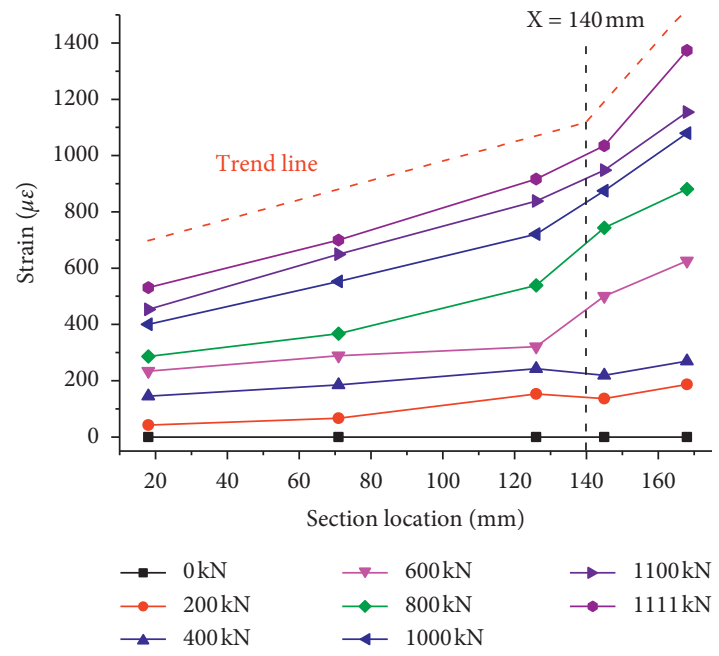

(d)

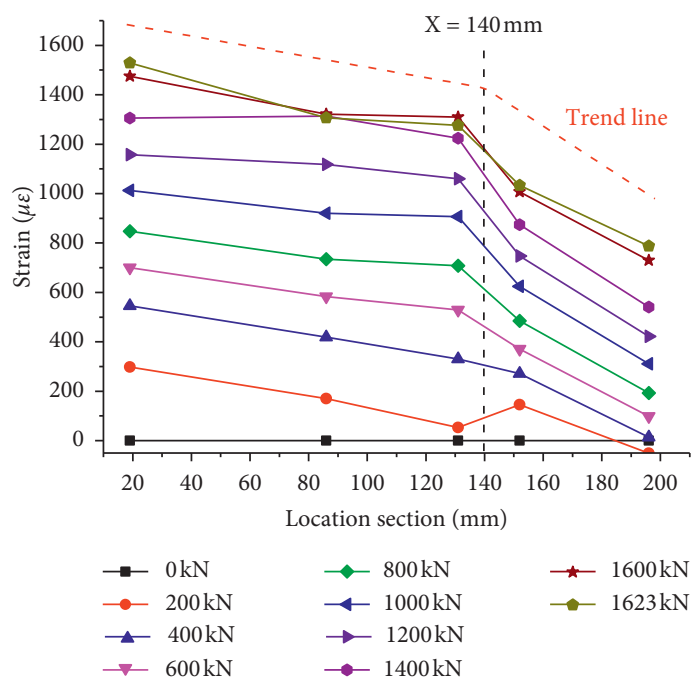

(e)

FIGURE 10: Strain distribution of group U. (a) U35-L-20-1. (b) U35-L-40-1. (c) U35-R-20-1. (d) U35-R-30-1. (e) U70-L-20. 
TABLE 6: Measured values of bearing capacity and strain at failure.

\begin{tabular}{|c|c|c|c|c|c|c|}
\hline \multirow{2}{*}{$\begin{array}{l}\# \\
1\end{array}$} & \multirow{2}{*}{$\begin{array}{l}\text { Notation } \\
\text { P00-L-00 }\end{array}$} & \multirow{2}{*}{$\begin{array}{c}\text { Ultimate bearing } \\
\text { capacity }(\mathrm{kN})\end{array}$} & \multicolumn{2}{|c|}{$\begin{array}{l}\text { Original structure } \\
(\mu \varepsilon)\end{array}$} & \multicolumn{2}{|c|}{$\begin{array}{l}\text { Reinforcement layer } \\
(\mu \varepsilon)\end{array}$} \\
\hline & & & - & - & - & - \\
\hline 2 & P00-L-30 & 682 & - & - & - & - \\
\hline 3 & N70-L-00 & 1630 & 1183 & 1282 & 1197 & 1348 \\
\hline 4 & N70-L-20 & 1660 & 1892 & 865 & 865 & 371 \\
\hline 5 & N70-L-30 & 1242 & 1527 & 725 & 662 & 308 \\
\hline 6 & N70-L-40 & 992 & 1100 & 457 & 562 & 386 \\
\hline 7 & U35-L-20-1 & 1249 & 1342 & 937 & 700 & 480 \\
\hline 8 & U35-L-20-2 & 1198 & 1305 & 829 & 743 & 434 \\
\hline 9 & U35-L-40-1 & 914 & 1345 & 525 & 525 & 213 \\
\hline 10 & U35-L-40-2 & 841 & 1480 & 326 & 326 & 121 \\
\hline 11 & U35-R-20-1 & 1375 & 732 & 1035 & 1035 & 1544 \\
\hline 12 & U35-R-20-2 & 1354 & 837 & 1051 & 880 & 1539 \\
\hline 13 & U35-R-30-1 & 1111 & 537 & 925 & 925 & 1506 \\
\hline 14 & U35-R-30-2 & 1135 & 490 & 934 & 934 & 1543 \\
\hline 15 & U70-L-20 & 1623 & 1600 & 1100 & 1100 & 707 \\
\hline
\end{tabular}

layer included brick cracking, the detachment of the reinforcement layer, the development of cracks on the layer surface, brick crashing, layer cracking, and the formation of hinges [29], and so do the failure process of concrete arch bridge reinforced with UHPC. However, the segment model test cannot continue to carry out the load process of the UHPC reinforcement layer alone because the original structure crushing marks the end of the test, so the segment model test fails to fully reflect the advantages of UHPC reinforcement. In the future, the test of a plain arch bridge with UHPC composite arch circle should be carried out to draw a more complete conclusion.

According to the values collected on the section, the strain values of both sides of the original structure and the reinforcement layer can be calculated. The strain values of each test piece are all summarized in Table 6. For L-side loading, the maximum compressive strain is more than $1300 \mu \varepsilon$ except for N70-L-40, and it is above $1500 \mu \varepsilon$ for $\mathrm{R}$-side loading. It is worth noting that the maximum compressive strain of the UHPC reinforcement layer is up to $1500 \mu \varepsilon$ when the load is applied to the R-side, but it is far lower than the peak compressive strain. At the same time, the strain of NC at the interface is generally less than $1000 \mu \varepsilon$, and it is also lower than the compressive strain for L-side loading specimens, which indicates that the concrete crushing is not the main factor of failure. Combined with the failure mode of R-side specimens, it is the first crack in the concrete at the upper end interface that causes the failure of the specimens. It can be inferred that the failure of the group $U$ specimen loaded on the $\mathrm{R}$-side is caused by microcracks at the interface.

3.4. Analytical Investigation of Segment Models. As exhibited in Figures 7 and 8, a linear relationship between the load and strain can be found most of time during the loading process. Therefore, the bearing capacity of the specimen can be obtained through the calculation of the stresses of the original structure and the reinforcement layer. The load-carrying capacity of specimens can be evaluated as follows:

$$
\begin{aligned}
N_{u 1} & =\sigma_{1} A_{1}+\sigma_{2} A_{2}, \\
\sigma & =E \varepsilon,
\end{aligned}
$$

where $N_{u 1}=$ the theoretical calculation value, $\sigma_{1}=$ the average stress of the original structure, $A_{1}=$ the compression area of the original structure, $\sigma_{2}=$ the average stress of the reinforcement layer, $A_{2}=$ the compression area of the reinforcement layer, $\sigma=$ the average stress of the original structure or reinforcement layer, $E=$ the elastic modulus of the original structure or reinforcement layer, and $\varepsilon=$ the average strain of the original structure or reinforcement layer.

The load shared by the original structure $\left(N_{u 11}\right)$ and the reinforcement layer $\left(N_{u 12}\right)$ at failure is listed in Table 7 , as well as the proportion of the reinforcement layer bearing the total load $\left(N_{u 12} / N_{u 1}\right)$. The theoretical value calculated is close to the test value, and the error can be basically controlled within $10 \%$. There are two possible reasons for the error. One is that the stress-strain curve of concrete is relatively complex. When it is close to the peak compressive strain of concrete, the stress and strain show nonlinear characteristics, which are simply considered as linear here. The other is that the failure sections of the test pieces are not all in the middle of the test pieces, and the measured strain value does not fully represent the strain state of the failure section.

In addition, the increase of eccentricity will reduce the overall bearing capacity of the specimens, but it will not significantly affect the load proportion of the reinforcement layer. The load proportion of the reinforcement layer is greatly affected by the thickness of the reinforcement layer and the loading position. From the result of this test, the increase of the thickness of the reinforcement layer can improve the load proportion of the reinforcement layer. When the eccentric load acts on the R-side, the load proportion of the reinforcement layer is significantly higher than that of the L-side.

Considering that the strain distribution on the cross section is unknown in the process of engineering application, it is difficult to apply the abovementioned method in the actual process. According to the calculation method of 
TABLE 7: Measured and calculated value of segment models.

\begin{tabular}{lccccccccc}
\hline$\#$ & Notation & $N$ & $N_{u 11}$ & $N_{u 12}$ & $N_{u 1}$ & $N_{u 12} / N_{u 1}$ & $N / N_{u 1}$ & $N_{u 2}$ & $N / N_{u 2}$ \\
\hline 1 & P00-L-00 & 1108 & - & - & - & - & - & 1111 & 1.00 \\
2 & P00-L-30 & 682 & - & - & - & - & 0.35 & 1.07 \\
3 & N70-L-00 & 1630 & 1156 & 614 & 1770 & 0.35 & 0.92 & 1798 \\
4 & N70-L-20 & 1660 & 1293 & 298 & 1591 & 0.19 & 1.04 & 1455 \\
5 & N70-L-30 & 1242 & 1056 & 234 & 1290 & 0.18 & 0.96 & 1284 \\
6 & N70-L-40 & 992 & 730 & 229 & 959 & 0.24 & 1.03 & 1113 \\
7 & U35-L-20-1 & 1249 & 1068 & 185 & 1254 & 0.15 & 1.00 & 1119 \\
8 & U35-L-20-2 & 1198 & 1000 & 186 & 1187 & 0.16 & 1.01 & 1119 \\
9 & U35-L-40-1 & 914 & 877 & 116 & 993 & 0.12 & 0.92 & 788 \\
10 & U35-L-40-2 & 841 & 847 & 70 & 917 & 0.08 & 0.92 & 788 \\
11 & U35-R-20-1 & 1375 & 828 & 406 & 1234 & 0.33 & 1.11 & 1.07 \\
12 & U35-R-20-2 & 1354 & 885 & 381 & 1266 & 0.30 & 1.07 & 119 \\
13 & U35-R-30-1 & 1111 & 685 & 382 & 1068 & 0.36 & 1.04 & 1.06 \\
14 & U35-R-30-2 & 1135 & 667 & 390 & 1057 & 0.37 & 1.07 & 953 \\
15 & U70-L-20 & 1623 & 1266 & 569 & 1835 & 0.31 & 0.88 & 1.21 \\
\hline
\end{tabular}

PLC members under eccentric load in reference [27], assuming that the axial force action point coincides with the concrete resultant force point in the compression area, at the same time, neglecting the contribution of longitudinal bars in the reinforcement layer to the structural bearing capacity and the difference caused by the different strength of reinforcement layer materials, the ultimate bearing capacity of the specimens is calculated by the following formula:

$$
N_{u 2}=\varphi f b\left(h-2 e_{0}\right),
$$

where $N_{u 2}=$ the theoretical calculation value; $\varphi=$ the stability coefficient of PLC members; $f=$ the measured cube compressive strength value; $b=$ the section width; $h=$ the section height; and $e_{0}=$ eccentricity.

The theoretical calculation value $\left(N_{u 2}\right)$ by this method and the test value $(N)$ are also placed in Table 7 . In the calculation of the bearing capacity of specimens under L-side load, most of the errors are controlled within 10\%, a few within $16 \%$. But, the errors are all more than $15 \%$ in the calculation of the bearing capacity of group $U$ under R-side loading. The reason for this phenomenon is that the same material is assumed in the calculation, and the influence of higher elastic modulus of UHPC is ignored. In similar calculation, the reinforcement effect of the material difference on bearing capacity can be considered. In this experiment, the increase factor of $15 \%$ can be considered when the bearing capacity of the group $U$ specimen under R-side loading is calculated, making their ratios all range from 1 to 1.1 , which ensures not only the accuracy of the calculation but also the safety of the structure.

\section{Conclusions}

In this paper, segment models were carried out to analyze the failure mode, strain distribution, and calculation of bearing capacity of a PLC arch bridge reinforced with UHPC arch circle. Variable parameters such as eccentricity, loading direction, and the thickness of the reinforcing layer were studied. According to the distribution of strain on the section, the bearing capacity of segment models was calculated, and a simple method was optimized for the convenience of engineering application. The main conclusions of this study can be summarized as follows:

(1) The bond strength between the original structure and a UHPC reinforcement layer is reliable by the technology of chiseling and planting bars. A much thinner reinforcement layer with fewer steel bars is needed because the high compressive strength and good bending resistance of UHPC are suitable for an arch bridge, which is convenient for repair work.

(2) The failure of group $P$ was sudden for the lack of longitudinal steel bars. The concrete crushing of the original structure was the main failure of the group $N$, and the reinforcement layer of some specimens showed visible cracks. However, there were no cracks on the surface of the UHPC reinforcement layer in group $U$. The peeling of the interface and concrete crushing of the original structure were the failure characteristics of R-side loading and L-side loading specimens for group $U$, respectively.

(3) The strain distribution of the whole section conformed to the assumption of the plane section for group $N$. But, it did not meet the assumption of the plane section for group $U$, and the strain of the reinforcement layer was behind or ahead of the original structure. It was worth noting that the strain of UHPC was far lower than its peak compressive strain when the original structure was crushed, which showed that the UHPC reinforced layer still had a great bearing potential.

(4) With the increase of the thickness of the UHPC reinforcement layer, the load sharing ratio of the reinforcement layer would increase. R-side loading specimens had a higher load-sharing ratio than L-side loading specimens. For L-side loading, the increase of eccentricity would significantly reduce the load sharing ratio of the UHPC reinforcement layer and reduce the bearing capacity. For R-side loading, the change of eccentricity had a small 
impact. But, in general, the proportion of load shared by the reinforcement layer was low, no more than $40 \%$.

(5) The linear relationship between stress and strain was used to calculate the load-bearing conditions of the reinforcement layer and the original structure, respectively, and the error with the test value was within $10 \%$. When a simplified calculation formula was adopted, the bearing capacity of group $U$ specimens under R-side loading was low, and the increase factor of $15 \%$ can be considered to improve calculation accuracy.

(6) At the moment of the original structure concrete crushing, the strain of the UHPC reinforcement layer was far lower than its peak compressive strain, and the UHPC reinforcement layer was intact without any cracks and had great bearing potential. However, the segment model test cannot continue to carry out the load process of the UHPC reinforcement layer alone because the original structure crushing meant the termination of the test. That is to say, segment models could only describe the crack development, strain distribution, and bearing capacity of the structure before the reinforcement layer was damaged and failed to reflect the whole failure process of PLC arches strengthened with UHPC composite arch circle. A full-scale reinforcement test of a PLC arch bridge should be carried out to draw a more complete conclusion in the future.

\section{Data Availability}

The experimental data used to support the findings of this study are included in the article.

\section{Conflicts of Interest}

The authors declare that they have no conflicts of interest.

\section{Acknowledgments}

The authors acknowledge the support of the National Natural Science Foundation of China (Grant no. 51908093), the Science and Technology Research Program of Chongqing Municipal Education Commission (KJQN201900733), and the Science and Technology Project of Guizhou Provincial Transportation Department (2018-123-001).

\section{References}

[1] P. Wang, H. Chen, J. Zhou et al., "Failure mechanisms of CFRP-wrapped protective concrete arches under static and blast loadings: Experimental research," Composite Structures, vol. 198, pp. 1-10, 2018.

[2] F. Cakir and H. Uysal, "Experimental modal analysis of brick masonry arches strengthened prepreg composites," Journal of Cultural Heritage, vol. 16, no. 3, pp. 284-292, 2015.

[3] A. D'Ambrisi, F. Focacci, R. Luciano, V. Alecci, and M. De Stefano, "Carbon-FRCM materials for structural upgrade of masonry arch road bridges," Composites Part B: Engineering, vol. 75, pp. 355-366, 2015.

[4] E. Hamed, Z.-T. Chang, and O. Rabinovitch, "Strengthening of reinforced concrete arches with externally bonded composite materials: Testing and analysis," Journal of Composites for Construction, vol. 19, no. 1, Article ID 04014031, 2015.

[5] S. Guan-jun, The Study on Performance Concrete Composite Arch Reinforced with CFRP, Chongqing Jiaotong University, Chongqing, China, 2013.

[6] T. Zhi-gang, The Study on Performance of Concrete Arch Reinforced with GFRP, Chongqing Jiaotong University, Chongqing, China, 2011.

[7] L. Garmendia, J. T. San-José, D. García, and P. Larrinaga, "Rehabilitation of masonry arches with compatible advanced composite material," Construction and Building Materials, vol. 25, no. 12, pp. 4374-4385, 2011.

[8] V. Alecci, F. Focacci, L. Rovero, G. Stipo, and M. De Stefano, "Intrados strengthening of brick masonry arches with different FRCM composites: Experimental and analytical investigations," Composite Structures, vol. 176, pp. 898-909, 2017.

[9] A. Nanni, "A new tool for concrete and masonry repair," Concrete International, vol. 34, 2012.

[10] F. A. Kariou, S. P. Triantafyllou, and D. A. Bournas, "TRM strengthening of masonry arches: An experimental investigation on the effect of strengthening layout and textile fibre material," Composites Part B: Engineering, vol. 173, Article ID 106765, 2019.

[11] F. G. Carozzi, C. Poggi, E. Bertolesi, and G. Milani, "Ancient masonry arches and vaults strengthened with TRM, SRG and FRP composites: Experimental evaluation," Composite Structures, vol. 187, pp. 466-480, 2018.

[12] V. Alecci, G. Misseri, L. Rovero et al., "Experimental investigation on masonry arches strengthened with PBO-FRCM composite," Composites Part B: Engineering, vol. 100, pp. 228-239, 2016

[13] B. A. Tayeh, B. H. Abu-Bakar, M. A. M. Johari, and Y. L. Voo, "Utilization of ultra-high performance fibre concrete (UHPFC) for rehabilitation-A review," Procedia Engineering, vol. 54, pp. 525-538, 2013.

[14] J. Yang, J. Zhou, Z. Wang, Y. Zhou, and H. Zhang, "Structural behavior of ultrahigh-performance fiber-reinforced concrete thin-walled arch subjected to asymmetric load," Advances in Civil Engineering, vol. 2019, pp. 1-12, Article ID 9276839, 2019.

[15] M.-G. Lee, Y.-C. Wang, and C.-T. Chiu, “A preliminary study of reactive powder concrete as a new repair material," Construction and Building Materials, vol. 21, no. 1, pp. 182-189, 2007.

[16] M.-A. Dagenais, B. Massicotte, and G. Boucher-Proulx, "Seismic retrofitting of rectangular bridge piers with deficient lap splices using ultrahigh-performance fiber-reinforced concrete," Journal of Bridge Engineering, vol. 23, no. 2, Article ID 04017129, 2018.

[17] G. Martinola, A. Meda, G. A. Plizzari, and Z. Rinaldi, "Strengthening and repair of RC beams with fiber reinforced concrete," Cement and Concrete Composites, vol. 32, no. 9, pp. 731-739, 2010.

[18] K. Kobayashi and K. Rokugo, "Mechanical performance of corroded RC member repaired by HPFRCC patching," Construction and Building Materials, vol. 39, pp. 139-147, 2013.

[19] M. Safdar, T. Matsumoto, and K. Kakuma, "Flexural behavior of reinforced concrete beams repaired with ultra-high 
performance fiber reinforced concrete (UHPFRC)," Composite Structures, vol. 157, pp. 448-460, 2016.

[20] A. P. Lampropoulos, S. A. Paschalis, O. T. Tsioulou, and S. E. Dritsos, "Strengthening of reinforced concrete beams using ultra high performance fibre reinforced concrete (UHPFRC)," Engineering Structures, vol. 106, pp. 370-384, 2016.

[21] A. Meda, S. Mostosi, Z. Rinaldi, and P. Riva, "Corroded RC columns repair and strengthening with high performance fiber reinforced concrete jacket," Materials and Structures, vol. 49, no. 5, pp. 1967-1978, 2016.

[22] B. A. Tayeh, M. A. Naja, S. Shihada, and M. Arafa, "Repairing and strengthening of damaged RC columns using thin concrete jacketing," Advances in Civil Engineering, vol. 2019, pp. 1-16, Article ID 2987412, 2019.

[23] C. Beschi, P. Riva, G. Metelli, and A. Meda, "HPFRC jacketing of non seismically detailed RC corner joints," Journal of Earthquake Engineering, vol. 19, no. 1, pp. 25-47, 2015.

[24] A. Marini and A. Meda, "Retrofitting of R/C shear walls by means of high performance jackets," Engineering Structures, vol. 31, no. 12, pp. 3059-3064, 2009.

[25] M. Preti and A. Meda, "RC structural wall with unbonded tendons strengthened with high-performance fiber-reinforced concrete," Materials and Structures, vol. 48, no. 1-2, pp. 249-260, 2015.

[26] M. Zhou, W. Lu, J. Song, and G. C. Lee, "Application of ultrahigh performance concrete in bridge engineering," Construction and Building Materials, vol. 186, pp. 1256-1267, 2018.

[27] China Architecture \& Building Press, Code for Design of Concrete Structures. GB 50010-2010, China Architecture \& Building Press, Beijing, China, 2015.

[28] China Communications Press, Specifications for Strengthening Design of Highway Bridges. JTG/T J22-2008, China Communications Press, Beijing, China, 2008.

[29] N. Simoncello, P. Zampieri, J. Gonzalez-Libreros, and C. Pellegrino, "Experimental behaviour of damaged masonry arches strengthened with steel fiber reinforced mortar (SFRM)," Composites Part B: Engineering, vol. 177, Article ID 107386, 2019. 